Kompass

Neumología

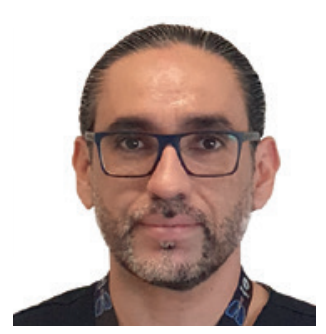

Arturo Cortés-Télles

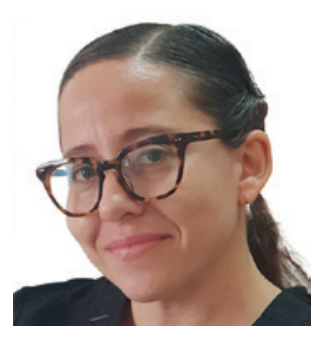

Esperanza Figueroa-Hurtado

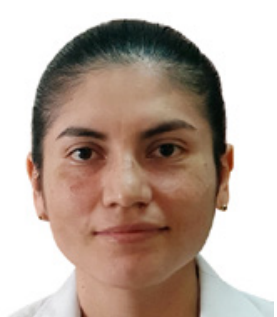

\section{Diana Lizbeth Ortíz-Farías}

Departamento de Neumología y Cirugía de Tórax, Hospital Regional de Alta Especialidad de la Península de Yucatán, Mérida, México

\title{
COVID-19 - La nueva cara de la desigualdad: Lecciones aprendidas a 2 años del inicio de la pandemia
}

Al editor,

Lejos queda el invierno del 2019 cuando una nueva enfermedad respiratoria - hoy se conoce como SARS-CoV-2 (severe acute respiratory syndrome coronavirus 2, síndrome respiratorio agudo severo coronavirus 2) cimbraba el poderoso continente asiático [1]. El origen, fue la provincia de Wuhan, que pasará a la memoria de millones de habitantes, al mismo tiempo, evocaban nuestros recuerdos del 2009 cuando México fue el epicentro de la pandemia por Influenza A H1N1, una nueva variante de un viejo y conocido enemigo. Todos nos maravillamos por la imponente estrategia en salud del gigante asiático con el objetivo de ampliar la cobertura hospitalaria ante la creciente demanda por la nueva enfermedad, construyeron hospitales plenamente equipados desde sus cimientos sumado a la conversión de hoteles en sedes hospitalarias para intensificar el aislamiento y seguimiento de los infectados y la fabricación de ventiladores mecánicos de última generación; así entonces, fuimos testigos del combate frontal ante una emergencia sanitaria y el principio del confinamiento en el mundo.

La otra cara de la moneda ocurrió en nuestro país; y posiblemente en otros de economías emergentes. La pandemia arribó en vuelos internacionales y a partir del primer caso reportado el 28 de febrero del 2020 los números crecieron exponencialmente con un comportamiento singular de oleadas, que en palabras de los profesionales de la salud se percibieron como maremotos, debido a la implementación de una estrategia controvertida y severamente criticada de vigilancia epidemiológica centinela, contraviniendo las recomendaciones internacionales sobre el tamizaje para identificar y aislar a los casos, minimizando las tasas de contagio. En paralelo, los responsables de las políticas de salud en México transmitían con tintes nihilistas un panorama nebuloso respecto a las medidas para contener la enfermedad, entre ellas, la subestimación del uso mascarillas entre la población y la escasa respuesta sobre las restricciones en movilidad que tradujeron una diseminación del COVID-19 (coronavirus disease 2019, enfermedad por coronavirus 2019) cual tsunami después de un terremoto en una sociedad diezmada y con gran desigualdad para accesar al sistemas de salud ; en el cual las personas con un ingreso mínimo presentan 5 veces mas riesgo de fallecer por la enfermedad [2]; en consecuencia, la difusión de imágenes desgarradoras de mexicanos clamando por auxilio médico y otras, capturando post mortem la evidencia de un sistema de salud fracturado con ausencia 
de la infraestructura básica para enfrentar a ese monstruo sin ambages ni eufemismos que estaba por mostrarnos su capacidad de diseminación y expresión, desde enfermedad leve hasta los casos graves con elevada mortalidad [3]. Los resúmenes mañaneros y vespertinos resultaban fuera de la realidad, proyectando el final de la cuarentena en Mayo del 2020. No obstante, los trabajadores de la salud fuimos testigos de iniciar una guerra sin tregua ni cuartel enfrentando al enemigo letal cuyo escenario catastrófico sería alcanzar 60 mil muertes; la realidad, México contabiliza más de 3 millones de casos confirmados y casi 300 mil muertes, la penosa cifra proyectada ha sido rebasada cinco veces y en la semana epidemiológica más obscura cobró 10,095 vidas de mexicanos [4]. Para que la cuña apriete, Amnistía Internacional publicó el 3 de septiembre del 2020 que la mortalidad en los trabajadores de la salud de México era alarmante (1,320 profesionales) contrastando con cualquier otro país [5]. Lo anterior, señalaba a México como el peor país para vivir durante la pandemia, donde la letalidad fue

\section{Referencias}

1 Zhu N, Zhang D, Wang W, et al.: A Novel Coronavirus from Patients with Pneumonia in China,2019. NEnglJ Med.2020;382(8):72733.

2 Arceo-Gomez EO, Campos-Vazquez RM, et al.: The income gradient in COVID-19 mortality and hospitalisation: An observational study with social security administrative records in Mexico. Lancet Reg Health Am. 2022;6:100115.

3 Cortes-Telles A, Lopez-Romero S, MancillaCeballos R, et al :Risk Factors for Mortality in Hospitalized Patients with COVID-19:An Overview in a Mexican Population. Tuberc Respir Dis (Seoul). 2020;83(Suppl. 1):S46-S54. triplicada por cada 100 casos documentados con prueba positiva y de manera significativa en adultos jóvenes debido a la presencia de otra pandemia silente, la obesidad y sus sindemias [6].

Ensayos clínicos alrededor del mundo desbordaron ríos de información reportando tratamientos médicos que disminuyen la mortalidad por COVID-19. Desafortunadamente y a pesar de la evidencia, algunos profesionales de la salud mantuvieron la prescripción de terapias fútiles que no modifican la mortalidad favoreciendo la evolución catastrófica de la pandemia en México. El desarrollo de las vacunas ocurrió en un tiempo sin precedentes debido al trabajo conjunto de científicos, biotecnólogos y al financiamiento de filántropos, esto ha permitido reiniciar actividades económicas, sociales y educativas debido al impacto positivo en la reducción de la mortalidad [7-10]. Así, luego de 2 años, debe quedar claro que la mejor medicina es la preventiva, además, invertir en infraestructura, equipamiento y capacitación del personal de las instituciones de salud que fortalezcan la implemen-

4 SINAVE. COVID-19, México: Datos epidemiológicos Dirección General de Epidemiología: Gobierno de México; 2021 (disponible enhttps://covid19.sinave.gob.mx/).

5 Agren D: Understanding Mexican health worker COVID-19 deaths. Lancet. 2020; 396(10254):807.

6 CRC. Mortality Analyses: Johns Hopkins University \& Medicine; 2021 ( disponible en https://coronavirus.jhu.edu/data/mortality).

7 Voysey M, Clemens SAC, Madhi SA, et al.: Safety and efficacy of the ChAdOx1 nCoV-19 vaccine (AZD1222) against SARS-CoV-2:an interim analysis of four randomised controlled trials in Brazil, South Africa, and the UK. Lancet. 2021;397(10269):99-111. tación de manejos basados en evidencia, los cuales modifiquen el pronóstico de la enfermedad. También incentivar a los profesionales de la salud a permanecer en retroalimentación mediante programas de educación médica continua y entenderlo como una tercera oportunidad de cimentar con solidez las bases hacia un futuro más claro en la atención de casos por COVID-19. Ciertamente, nos quedan lecciones por aprender de esta emergencia sanitaria, dado que, la historia aún no termina de escribirse.

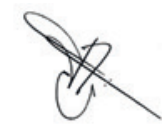

Dr. Arturo Cortés-Télles

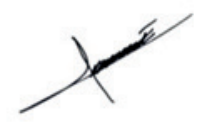

Dra. Esperanza Figueroa-Hurtado

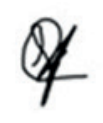

Dra. Diana Lizbeth Ortíz-Farías
8 Baden LR, El Sahly HM, Essink B, et al.: Efficacy and Safety of the mRNA-1273 SARSCoV-2 Vaccine. N Engl J Med. 2021;384(5): 403-16.

9 Polack FP, Thomas SJ, Kitchin N, et al.: Safety and Efficacy of the BNT162b2 mRNA Covid-19 Vaccine. N Engl J Med. 2020;383(27): 2603-15.

10 Bueno SM, Abarca K, Gonzalez PA, et al.: Safety and Immunogenicity of an Inactivated SARS-CoV-2 Vaccine in a Subgroup of Healthy Adults in Chile. Clin Infect Dis. 2021; ciab823. 